\title{
Impact of Continuing Education at the Directorate- General for Secondary Education on the Professionalization of Teachers
}

\author{
Moussavou Guy \\ Doctor in Education science, Teacher-researcher at Marien Ngouabi University of Congo - Member of LARCED Laboratory \\ Associate researcher at the CIRNEF Laboratory - University of Rouen- France
}

\begin{abstract}
This research is about the impact of staff training - in line with continuing education - on teachers' professionalization at the Secondary Education Management. It is true that one cannot fulfill any organization's objectives without going through the professionalization of its personnel. Our research paper led us to firstly look over a set of necessary theories required for sound staff training that goes hand in hand with professionalization of teachers. Then, on the basis of an empirical approach, we have drawn a parallel between the aforementioned theories and teachers' training performance at the Secondary Education Management. And this resulted in the identification of weaknesses noticed in continuing education management, prior to suggesting palliative measures.
\end{abstract}

Keywords: impact, continuing education or staff training, professionalization, secondary school teachers, professionalization requisites

\section{Introduction}

The issue of training has always been one of the major concerns of all societies. Our personal experience makes us realize that it remains relevant despite the passage of time and successive generations. The omnipresence of this question can not end as long as humanity as a whole continues to aspire to perfection, in cultural, economic, social, political and scientific terms; all the more so since it is related to the intrinsic nature of man and his aspirations, and for this purpose is as old as humanity. For if Jean Jacques ROUSSEAU wrote that "on this difference between man and animal, there is another very specific quality which distinguishes them, and on which there can be no dispute; it is the faculty of perfecting oneself, a faculty which, by the aid of circumstances, successively develops all the others. It is evident that since its appearance on earth the first and natural intention of man has always been to know and therefore to train or improve oneself in order to acquire what is today called competence.

The seniority of the question of formation does not, however, presuppose its completion, it remains whole, unfinished and inexhaustible. She has always been at the center of intellectual and pedagogical debates.

We can see its venerability in all organizations. Organizations have the particularity of always inserting the issue of vocational training into human resource management procedures. Is it because it would be considered the sine qua non of any progress?

It is at least obvious that in any organization, what is expected is the deployment of staff skills for good performance. These skills are acquired in the practice of the profession through experience acquired, but also through vocational training which is an effective means of building and rebuilding skills. This venerability of the question of vocational training shows its relevance in today's world, where competence is the repository of the employability of individuals in an organization.
The governments of the states which, among other obligations, the creation and the availability of a productive human capital, give it a place of choice in the order of their priorities. Hence, the survival of the problem of vocational training is justified and the need to continue to talk about it.

As much as we know that vocational training is not only a question of the past, but of the present and the future, it is necessary to know its impact. Because, every organization has always needed a competent staff.

This need is justified by the institutionalization of training in all States through the establishment of an educational system and at the international level through the establishment of specialized educational bodies, such as UNESCO.

The educational system, without a doubt, necessarily integrates in its programs the political and economic ends of the State. These are nothing more than the aspirations of the people and the ideological orientation of the state translated in terms of objectives by the educational system. This is at least the reason why education seems to be the basis of all development.

Through vocational training, the education system aims to build skills, that is, to produce cadres whose profile must be congruent with the social and economic project of a state for its development. This is what we read in article 4 of the school law which states that "the organization of education is a duty of the State. This education must provide each child with training adapted to modern life and school tasks and contribute to raising his standard of living ".

Seen under this prism, any educational system must be evaluated according to the impact of the training received by its beneficiaries. It is precisely to appreciate its performances. Because, the impact constitutes a determining indicator of any action.

In the Republic of Congo, the evaluation of the impact of training shows a gloomy picture, a sign of a continuing

\section{Volume 6 Issue 12, December 2017}




\section{International Journal of Science and Research (IJSR) \\ ISSN (Online): 2319-7064}

Index Copernicus Value (2016): 79.57 | Impact Factor (2015): 6.391

deterioration of the education system, which is characterized by the poor performance of schools in recent decades in all the sub-sectors of education. 'education. As can be seen in the results at the general and technical baccalaureate.

The Directorate General of Secondary Education (DGES), is one of the actors in education for general education. It holds our attention for the simple fact that in the day-to-day management of tomorrow's management training, it is required to ensure the professionalism of the teaching function, the reliability of the programs and the quality of the product.

Since its creation, the Directorate General of Secondary Education has mobilized a variety of resources, including human resources. This staff is composed of agents with initial training and agents without initial training. As we can see, the heterogeneity of this staff would be problematic if we did not consider accompanying measures.

As in any company or structure in charge of human resources, the Directorate General of Secondary Education knows that man is the most important resource to achieve its objectives. The obvious is that the principle of competence and qualification of staff is also fundamental. Hence the need for professional training.

Vocational training can be understood in its two aspects: first as a body of pedagogical devices offered to students for the acquisition of professional skills, in this case we speak of initial vocational training, and as a set of devices educational programs offered to workers or employees with a view to their adaptation to the new structural organization of the company or to technological developments, with a view to their professional progress, in this case we speak of continuing vocational training. The General Directorate of Secondary Education to meet this need, organizes continuous professional training sessions. What then are the learning contents of these training sessions? What are the objectives?

This preliminary questioning supports our research whose general objective is to show the impact of continuing vocational training on the professionalization of secondary school teachers.

For this purpose, our research work aims at proposing some pedagogical and technical approaches to the problems of vocational training at the Directorate General of Secondary Education on the professionalization of secondary school teachers. with a focus on continuing professional development for example.

In setting this goal, we have set ourselves the prospect of meeting, on the one hand, a personal need to work in a sector that interests us, and on the other hand, to respond to the needs for improving performance in the field. Education Sector of the Republic of Congo. This means that we specifically aim to: - present the strategies of the Directorate General of Secondary Education in terms of training; analyze its training plan $\bullet$ show the real impact of continuing vocational training as a lever for any progress and performance factor. It is said in management that "a cadre who does not form, becomes incompetent". In this sense, vocational training is a permanent device that must be at the heart of human resources management. It is for this reason that it has not escaped the reflection of certain thinkers who had resolved to carry out research on this question.

In 1993 C. THELOT, speaking about the evaluation of the education system, had shown the importance of continuing vocational training starting from a somewhat syllogistic approach. According to him, if the learner is the end of the instruction, the teaching staff is the main factor in the success of the learners. For this purpose, the in-service training of teaching staff should be preferred. For, no progress would be possible without him:

In 1997 INCHAUPE P. had analyzed the relationship between vocational training and the education system. He had relied on the Quebec model. In a historical analytical approach, he had shown that vocational training is the determining instrument of an educational system and the main lever of the performance of any company. Its necessity is as evident as in Quebec, in 1907, the creation of technical and vocational schools, which themselves were nothing other than the result of the evening classes which were given to the workers as early as 1872 and the academic response to the need for professional training that was already being felt:

In 2006 B. COTTONAR (cited by G. CHAPELLE, D. MAURET) focused on the issue of continuing professional development in schools. According to him, this training is of paramount importance given the complexity of the educational relationship due to the heterogeneity of the school public.

In 2015, in our own work (MOUSSAVOU, 2015), we analyzed the concept of professionalization of teachers, to highlight the impact of vocational training. Taking as reference the teachers without initial training in Gabon, we showed that vocational training allows the professionalization of individuals, activities and the education system.

As we can see, all of these studies had the main ambition of justifying the importance of vocational training in general and its impact on the education system. They have proved that vocational training is a no less negligible lever of progress, whose programs and the means implemented determine its impact. Also, for this research, we asked ourselves the question of research in the following way: is the impact of vocational training at the Directorate General of Secondary Education on the professionalization of teachers This research question leads us to formulate the hypothesis that the impact of vocational training to the Directorate General of Education Secondary is professionalisation, which is characterized by: professionalization of teachers (variable 1) $\square$ professionalization of programs (variable 2) $\square$ the professionalisation of the education system (variable 3). Our initial hypothesis was built on the basis of the studies read in the world literature on the importance of vocational training, but we will focus on in this research on the data that we will collect in the field. It is in this sense that this work has been guided by a technique of documentary research, and

\section{Volume 6 Issue 12, December 2017}




\section{International Journal of Science and Research (IJSR) \\ ISSN (Online): 2319-7064}

Index Copernicus Value (2016): 79.57 | Impact Factor (2015): 6.391

investigation by interview. It consists of an introduction containing the context, the research question and the hypothesis, the methodology including tools, results obtained, synthesis and discussion, suggestions and concludes with a conclusion.

\section{Methodological Approach}

\subsection{Impact of continuing vocational training at the Directorate General of Secondary Education}

The purpose of this chapter is to present and analyze data on different sources of information, which we used to measure the impact and implementation of continuing vocational training, offered to secondary school teachers at secondary school level. the general directorate of secondary education. It is structured in two sections, each with two paragraphs.

\subsubsection{Data collection tools}

\section{Sample}

Far from considering the overall enrollment of secondary school teachers, we estimated a sample of 25 teachers for our survey, in order to carry out a qualitative rather than a quantitative analysis. Although five (5) teachers did not attach importance to our requests by refraining from exchanging with us, twenty (20) teachers at least participated in the survey. Six (6) themes formed the backbone of our methodological approach whose technique of highlighting knowledge is "questions and answers"

Investigation by document analysis.

In this research and according to the variables of our research hypothesis, we proceeded to the analysis of the documents related to the organization, the documentation and the thematic programming of the continuous training actions. For this purpose, our documentary analysis will use the analysis on:

- Colloquia;

- Seminars;

- Educational animations.

\section{Interview survey}

We opted for semi-structured interviews, which allowed us to discover the opinions, aspirations, perceptions, values and convictions of teachers. The indices being personal to each teacher, we were interested in the services in charge of personnel and pedagogy at the general directorate of secondary education, and the active teachers who participated as beneficiaries in the various continuing education actions in the schools. educational institutions. To this end, we spoke with five (5) agents in the general direction of secondary education because of an agent in the following departments: DLEG (direction of high schools general education), DAAF (direction of business administrative and financial), SRH (human resources department), SAA (administrative service), SP (personnel department), and five (5) teachers at the institution " A ", five (5) at the " B " establishment, five (5) at " $\mathrm{C}$ " and five (5) at " D " establishment.

Since not all teachers were available, we used open-ended interviews. This approach, as mentioned above, responded to the interest of seeing each teacher express his opinions freely.

Our items have been formulated according to the following themes:

- The identity of the teachers;

- The task and activity of teachers;

- Collaborative work;

- Support for teachers

- Teacher development;

- The subjectivity of teachers on their work.

\section{Analysis and Interpretation of the Results}

\section{Documentary analysis}

As we have announced, the ele

a) On symposia

\begin{tabular}{|c|c|c|c|}
\hline Years & Disciplines & $\begin{array}{c}\text { Localities of } \\
\text { trained } \\
\text { beneficiaries }\end{array}$ & $\begin{array}{c}\text { Localities of } \\
\text { untrained } \\
\text { beneficiaries }\end{array}$ \\
\hline 2013 & $\begin{array}{c}\text { LVE, , Physical } \\
\text { Sciences, Maths }\end{array}$ & Brazzaville & 11 departments \\
\hline 2014 & French, Philosophy & $\begin{array}{c}\text { Brazzaville, } \\
\text { Pointe Noire }\end{array}$ & 10 departments \\
\hline 2016 & History Geography & Brazzaville & 11 departments \\
\hline 2017 & $\begin{array}{c}\text { LVE, Physical } \\
\text { Sciences, Maths, } \\
\text { French, Philosophy, } \\
\text { History Geography }\end{array}$ & Owando & 10 departments \\
\hline
\end{tabular}

Source : SRH

This table indicates that continuing vocational training actions, in the context of seminars, do not cover all localities. It is just a very small number of teachers who take part in these meetings, the largest number of teachers is abandoned. This means that symposia organized with the aim of bringing about innovations in teaching work, with reference to new pedagogical practices, should be organized in all departments for all secondary school teachers. Because, the professionalization of the individual teachers concerns each teacher. It is the individual alone, taking part in the training that is transformed in his way of doing the class. This condition alone makes possible the professionalization of activities and consequently that of the education system. The neglect of some of the teachers at the symposia could pose the problem of evaluation of these continuing education actions. The analysis of these data has led us to question the palliative measures planned by the Directorate General of Secondary Education on this subject. We thought to check this through our interviews with teachers.

\section{b) Teacher capacity building seminars on ICTs (new} information and communication technologies)

\begin{tabular}{|c|c|c|}
\hline Years & Disciplines (formed) & Disciplines (untrained) \\
\hline 2016 & $\begin{array}{c}\text { SVT, Physical } \\
\text { Sciences, Maths }\end{array}$ & $\begin{array}{c}\text { History Geography, } \\
\text { Philosophy, French, LVE, }\end{array}$ \\
\hline 2017 & Same & Same \\
\hline
\end{tabular}

Source: Reports

Reading the data in this table shows that the use of new information and communication technologies is not yet

\section{Volume 6 Issue 12, December 2017}




\section{International Journal of Science and Research (IJSR) \\ ISSN (Online): 2319-7064}

Index Copernicus Value (2016): 79.57 | Impact Factor (2015): 6.391

effective. More than the majority of teachers have not yet appropriated the computer tool to integrate it into teaching work.

The analysis of his data also highlighted the fact that only the scientific subjects that were selected for the ICT seminar. This certainly indicates either negligence or lack of knowledge of the use that can be made of new information and communication technologies in unselected disciplines. In reality, these technologies can be very useful in learning the rules of language functioning (LVE); the study of certain geographical phenomena (History and Geography); the biobibliographic study of authors (French and Philosophy). The use of slides would be desirable in all disciplines.

c) Zonal educational animations (case of zone 1)

\begin{tabular}{|c|c|c|}
\hline Educational Departments School & \multicolumn{2}{|c|}{ Year 2015-016 } \\
\cline { 2 - 3 } & \% participation & $\%$ absence \\
\hline Philosophy & 35 & 65 \\
\hline Frech & 41 & 59 \\
\hline Geography history & 38 & 62 \\
\hline Mathématics & 43 & 57 \\
\hline SVT & 36 & 64 \\
\hline LVE & 42 & 58 \\
\hline Physical Sciences & 45 & 55 \\
\hline
\end{tabular}

Source: Reports Inspection of high schools in zone 1 (Brazzaville, Pool, Sangha, Likouala).

The reading of this table reveals a bad observation, from a low participation rate of teachers to continuing education actions in the context of municipal educational events. On the other hand, the number of absentees is very high. This situation having caught our attention, we formulated a maintenance item to understand this phenomenon. Because, these rates can negatively influence the impact of continuing vocational training of secondary teachers from the first variable which is the professionalization of individuals.

\section{Results of the interviews}

After the documentary analysis, the interview appears for us as an effective possibility of verifiability of the impact of continuing vocational training on secondary school teachers. Since it is a question of making people speak for themselves, their opinions, convictions, theories and ways of being at work are of paramount importance in the perspective of qualitative inquiry.

Theme 1: Teacher Identity Our main objective here is to find out if the teachers surveyed all have basic vocational training.

The words of the teachers interviewed show us that they all have university level.

From the point of view of duration in education, the teachers surveyed have a seniority ranging from 5 to 30 years. This is indicative of the experience gained and the reliability of the data to be collected from them. However, almost half of the respondents have seniority ranging from 6 to 10 years. They have acquired a professionalism that can benefit other less experienced teachers.
The majority of these secondary school teachers have initial vocational training. Still five (5) teachers surveyed did not undergo teacher training. This shows that the Congolese State uses teachers without basic vocational training. It is therefore obvious that there is a heterogeneity of secondary school teachers. This situation suggests the obligation for the Directorate-General for Secondary Education to prioritize continuing training in order to give professionalism to these teachers without basic vocational training.

Our survey also revealed that sometimes teachers, according to their skills, find themselves in college. These teachers also indicate that the basic vocational training received is insufficient. It is obvious that basic vocational training alone is not enough to acquire the skill. In fact, initial teacher training leads to certification of the qualification to practice the teaching profession, but competence is acquired through experience through the various continuing training actions that take place throughout the working life.

This theme also emphasizes that the beginnings of teaching work like any other work are difficult. This assumes that teachers gain mastery of the job in the field. Addiction is a determining factor in the eradication of difficulties related to the practice of the class. This observation is undoubtedly the affirmation of the words of teachers investigated the shortcomings of initial training. Teachers usually arrive at their workplace not sufficiently trained, from the point of view practical knowledge and tools needed to do the class.

However, despite the difficulties of teaching work, more than half of the respondents enjoy their job positively.

Regarding the teaching profession, he continues to attract Congolese who do not hesitate to engage in it by personal conviction. They exercise it with love.

On the other hand, 7 teachers interviewed admit having chosen the teaching work because they did not find better elsewhere. That is to say, in the full employment situation these teachers would have opted for other professions. They were therefore guided by the " need to belong ", as expressed in Abraham Maslow's hierarchy of needs hierarchy (Maslow's Pyramid of Needs).

Theme 2: the task and activity of teachers.

Most teachers acknowledged that they had difficulty preparing the class. This is a crucial step in teaching work. It takes into account learners' level of understanding in order to properly select the appropriate methods, techniques, processes, media and language level for the class. The skills to lead this stage are acquired through experience. It integrates the dimension of practical knowledge or knowledge through experience. This is at least what one can grasp of this sentence "This knowledge is built gradually and fall within temporalities" of "beginning-and-end" (Moussavou, 2015). This means that teachers have theoretical knowledge when entering teaching work, and by practice they develop teaching skills.

However, it can be emphasized that the pedagogical difficulties experienced by teachers have an influence on the quality of teaching work, the quality of the education system

\section{Volume 6 Issue 12, December 2017}




\section{International Journal of Science and Research (IJSR) \\ ISSN (Online): 2319-7064}

Index Copernicus Value (2016): 79.57 | Impact Factor (2015): 6.391

and the quality of the product. It is obvious that the individual skills of the agents are one of the determining factors of the organization's situation, ie the performance of the organization.

With regard to homework, they are part of the means of student assessment. The large number of teachers surveyed use class assignments to probe the actual level of learners. Seven (7) teachers find in classroom assignments an opportunity to evaluate their own skills. In any case, it is obvious that the evaluation is apprehended by these teachers in its original sense. It allows a balance analysis of the work done to make a value judgment on their way of practicing teaching work. It is a self-criticism that signals the will to perfect oneself. On the strategies used to make the class, it must be emphasized that more of the majority of them relies on reading to enrich their knowledge and skills. Three (3) of the respondents rely on exchanges of experiences with the elders in the profession. This is continuous professional selftraining. It was understood in the first as in the second case, that teachers interviewed are aware of this aspect of continuing education. When we set ourselves in the perspective of Eurydice (1995) quoted by G. Masselter (2004), it is certain that this training allows them to improve "professional skills and competences through the acquisition of basic skills and updating of didactic and disciplinary knowledge ". We have likened this choice of teachers' personal strategy to the concept of "professionalization of teachers by experience" that we have developed in our previous work. The tools, the processes, the activities, the formal as well as the informal means experienced by the teachers in the work situation make you acquire professionalism.

Theme 3: Collaborative work

This theme informs us about the existence or not of the work group and about the personal adherence of each teacher interviewed to the teaching team of his school and his discipline. It also indicates the contributions of the older and more experienced in the profession as to the collective educational preparation of courses and the resolution of certain pedagogical difficulties. Each teacher interviewed stated the existence of a collective work in his school. This presupposes the existence of good working relationships between teachers, otherwise this collective of work can not exist. It is a climate conducive to the development of professional skills through the exchange of experience.

Because, if in a climate of conflicting relations, the administration is blocked, the unmotivated personnel and the work does not advance and does not improve either, it is that obviously the agents do not improve under these conditions . However, as Elton Mayo points out, good interprofessional relationships have a double effect, namely the feeling of belonging to the group and the involvement in the work of each agent. In this climate the weakest from the point of view of professionalism are helped by the most experienced. It must be said that the work group integrates a form of continuous training called self-analysis and self-training. This approach is in line with that articulated by $M$. Brousseau and P. Laurin (1997), according to which in the formation the reflexive aspect consists in "making explicit the implicit presuppositions to the practice". Indeed, each teacher has beliefs and conceptions of learning and teaching. Through collective work, the teacher readjusts his interventions in class and discovers that the beliefs of learning and teaching that he has, "influence the coherence of classroom interventions and consequently educational success. (Ibid) For these teachers, the contribution of colleagues contributes informally to the construction of their skills. Teachers adhere to collective work because it is one of the means of their professionalization through continuing education that can have "an interactive and reflexive orientation" (G. Masselter, op.cit). This training model focuses on problem solving and professional practice. It takes into account the experience of teachers and tries to bring new professional knowledge to teachers.

\section{Theme 4: Teacher support}

At this level we wanted to measure the formal support of inspectors, heads of departments, directors of studies, principals and other pedagogical supervisors. It is precisely to seek to see the impact of the various mechanisms put in place by the Congolese education system for the professionalization of teachers.

Inspectors and pedagogical consultants are the most immediate trainers of teachers in schools. The majority of teachers surveyed recognize that educational inspectors and tutors contribute to the development of professional skills.

\section{Theme 5: Teacher Development}

Through this theme, we learned about the networks or mechanisms that the teacher has built and the resources he mobilizes to build teacher professionalism. Here, continuing education actions in the context of capacity building seminars are conducted in secondary education. More than half of the teachers surveyed say they participated in the capacity building seminars. This proves that secondary education takes into account this instrument of motivation and improvement of the performance of the organization which is continuous training. There is therefore a close link between the performance of the organization and the skills of its agents. The more trained the agents, the better the performance.

In-service training of agents meets the recognition and intellectual development needs of trained teachers. However, eight (8) out of the 20 teachers interviewed have not yet taken part in the capacity building sessions. This not only keeps them ignorant of the new ideas of the teaching profession, but creates frustration that is recognized as an unmet need.

There is also the fact that the majority of teachers have never benefited from the symposia. Since the colloquium is a model of continuing education that brings great reforms in the practice of the classroom, it is unfortunate to restrict this space to too few teachers.

Regarding the seminars, they have a considerable impact on the teachers interviewed in the practice of their profession. This shows that high school teachers professionalize through seminars and symposia which are continuous training actions. More than the majority of teachers surveyed recognize that these continuing education actions contribute

\section{Volume 6 Issue 12, December 2017}




\section{International Journal of Science and Research (IJSR) \\ ISSN (Online): 2319-7064}

Index Copernicus Value (2016): 79.57 | Impact Factor (2015): 6.391

to the development of skills. Indeed, as Eurydice (1995) points out, continuing training remedies the shortcomings of initial training and its efforts are more concerned with the disciplines and the updating of the skills of the teaching staff ". Theme 6: the subjectivity of teachers on their work On this theme we seek to obtain teachers interviewed information on how they think their job as a teacher. The evidence that has emerged here is that with or without initial training it is not possible to become a competent teacher. This assumes that professional competence is also acquired through the different training courses that one receives during a career. These allow the teacher to adapt to the growing demands of society, to educational innovations and to acquire professionalism. Teachers emphasize that it is the experience in the profession that differentiates the teacher. experienced novice teacher. Experience is, so to speak, a factor and an index of professionalism. On the other hand, individual professionalisation must be a concern for teachers. The majority of them favor openness towards others to improve themselves, that is to say, the exchange of experience with colleagues. The renewal of knowledge can be done through what is called self-learning through reading, exchanges with other teachers, or by disciplinary software still called sources of online documentation. On the other hand, the Congolese education system is variously appreciated. The answers gathered from the teachers interviewed show that it is a system that is failing and is struggling to find efficiency. The poor quality of the Congolese education system can be explained by the poor quality of the product of this system. That is to say, the low level of learners reflects the failings of the education system. There is also the poor quality of the teaching programs as well as the lowering of the intellectual level of some teachers. We have confirmed here the close link that there is, from the point of view of impact, between the quality of the education system - the quality of the teacher - the quality of the product.

\section{Synthesis of the Results}

The approach adopted in our research work includes six (6) themes, namely: the identity of teachers; the task and activity of teachers; collaborative work; coaching teachers; teacher development; the subjectivity of teachers on their work. The six themes were analyzed.

This analysis showed in theme 1 on the identity of teachers that the Congolese education system not only uses teachers with basic vocational training, but also uses teachers without initial training. This proves that some of the secondary school teachers are not professional.

In theme 2, task and activity, we have shown that teachers find it difficult to teach in class. This justifies the relevance of continuing vocational training.

With regard to collaborative work (theme 3), the analysis has shown that there are working collectives in secondary schools called disciplinary departments in which continuing education activities are carried out in the context of local pedagogical activities. zonal. These contribute to the development of teachers' skills.
Turning to theme 4 on support, we have shown that inspectors and educational tutors carry out continuous training actions that contribute to building skills, particularly through class visits, seminars and educational activities.

Speaking of the improvement, at the level of theme 5 , the analysis showed that not all secondary school teachers benefit from seminars and symposia organized. A good part of the teachers (from the interior of the country) are not informed about the acquisition of these sessions; This leads to disparities in the practice of the class and the impossibility of evaluating the effects of the said seminars and seminars at the national level.

Finally, in theme 6 relating to the subjectivity of teachers to their work, we have taken the view that continuing training activities are not well organized because of the lack of financial resources allocated to training. However, the effects are positive in the localities where these actions are carried out. This proves that secondary school teachers acquire professionalism.

In short, the analysis of all the themes showed that when teachers benefit from in-service training sessions, they develop professional skills.

\section{Verification of Hypotheses and Suggestions}

After the previous chapter which returned the analysis of the collected data, in this chapter the objective is to note the verifiability of the variables of the hypothesis which we formulated for our research work and to formulate suggestions for a positive impact. vocational training of secondary school teachers.

\subsection{Verification of the hypotheses.}

To better guide our study, our research question "What is the impact of continuing vocational training in the Directorate General of Secondary Education on the professionalization of teachers", gave rise to a hypothesis segmented into three variables:

- The professionalization of teaching staff (variable 1);

- Professionalization of programs (variable 2);

- The professionalization of the education system (variable $3)$.

At the end of our work we found the following:

\section{Professionalization of teaching staff.}

Continuing education activities in secondary education contribute to the construction and development of teachers' professional skills. Our questions $(7,8,12,15,21)$ concerning the collective dimension of work, the mission of educational inspectors and tutors, capacity building sessions, training for the professionalization of teachers without initial training and the effects on field after continuous training, have shown that continuing vocational training makes the beneficiary teachers acquire professionalism. For this purpose, our hypothesis in its variable 1 is validated.

\section{Professionalization of Congolese educational programs and} system

Our hypothesis in its second variable states that, the impact of continuing vocational training at the general direction of

\section{Volume 6 Issue 12, December 2017}




\section{International Journal of Science and Research (IJSR) \\ ISSN (Online): 2319-7064}

Index Copernicus Value (2016): 79.57 | Impact Factor (2015): 6.391

secondary education on the professionalization of teachers is the professionalization of the programs. Our inquiry, based on the following questions $(6,11,13)$ concerning work groups within schools, the participation of teachers in symposiums, the impact of capacity building sessions on the teacher's work and the Congolese education system have shown that continuing education actions solve teachers' pedagogical difficulties by providing them with knowledge, know - how and know - how. This professionalism acquired by teachers is a determining factor in improving the quality of teaching work; because, since the teacher is professionalised, the activities are also professionalised by consequence. In this sense, this variable 2 also validates our hypothesis. As for the third and last variable of our hypothesis, it stipulates that the impact of continuing vocational training in the general direction of secondary education on the professionalization of teachers is the professionalization of the Congolese education system. Our investigation in all its questions and particularly in questions $8,12,13$ and 21 concerning the mission of inspectors and educational tutors, the impact of capacity building sessions on the performance of learners, the impact of the reinforcement sessions. the effects of continuing training in the field has shown that the distribution of continuing training activities at different local, sectoral, communal, zonal and national levels makes it possible to develop the skills of the teachers. teachers nationwide. To this end, they are a lever for professionalizing the entire education system. For, the professionalization of teachers leads to the professionalization of teaching work and the education system. Therefore, this variable also validates our hypothesis.

\subsection{Problems and suggestions}

\section{Paragraph 1: Problems.}

At the end of our study and the results of our surveys of secondary school teachers, we found that the Congolese education system, more specifically the general education sector, suffers from managerial problems, the most salient of which are present as follows:

- Lack of a training plan;

- Inefficient management of the agents' skills;

- Mismatch between trainer training, curriculum and product quality;

- Lack of sufficient funding for training.

\section{Paragraph 2: Suggestions.}

In view of the problems of secondary education, our suggestions concern the managers of the education system, the individuals, the activities and the educational system itself.

1) To the managers of the education system

- The establishment of a teacher training plan;

- The establishment of an evaluation system;

- The generalization of training in new information and communication techniques;

- The allocation of considerable funds to continuing education.

\section{2) To the teaching staff.}

Following the formulation of the suggestions for the managers of the education system, we want to reiterate that the professionalization of individuals implies a transmission of theoretical and practical knowledge to each individual, for the acquisition of professional skills. The individual is the fundamental target of vocational training. Its professionalization leads to that of activities and that of the education system. Therefore their participation in the various continuing education actions is mandatory. It is for this reason that we suggest:

- The implementation of vocational self-training;

- Constant participation in educational activities.

\section{3) With regard to programs}

The professionalization of teaching activities requires a focus on the quality of continuing education programs and methods. Only, the evidence is that the activities will never be professionalized except for a minority that benefits from continuing education actions. So we suggested:

- The generalization of continuing training activities throughout the Congolese territory;

- Assignment in educational establishments, especially within the country, of pedagogical supervisors;

\section{4) At the place of the education system}

The education system is the framework for determining the axes of education. Its value depends on the quality of the teaching programs, the quality of the initial and in-service teacher training and the quality of the product. The professionalization of an educational system being a process, we have made the following suggestions without denying the professional character of the Congolese education system affirmed in our hypothesis through its variables: redesign of basic teacher training programs in the USSR redesign of the learning content of continuing education, the systematic control of the holding of local and sectoral educational events.

\section{Conclusion}

Our study focused on the impact of continuing vocational training in the Directorate General of Secondary Education on the professionalization of teachers. By characterizing professionalization in a teaching environment, this study aims to be a contribution to the improvement of performance in the national education sector through the professionalism of teachers. As any study requires a research perspective, we focused our discussion on secondary school teachers whose governing body is the Directorate General of Secondary Education.

The basic intention presented at the introduction is to show the real impact of continuing professional development as a lever for any progress and a factor of performance development.

We have shown at the beginning that the impact of continuing vocational training in the general direction of secondary education is the professionalization of individuals, the professionalization of activities and the professionalization of the education system. 


\section{International Journal of Science and Research (IJSR) \\ ISSN (Online): 2319-7064}

Index Copernicus Value (2016): 79.57 | Impact Factor (2015): 6.391

The results we have achieved have shown that the continuous training of teachers meets several requirements: the prior knowledge of the needs of teachers and the failures of the education system through an evaluation, the determination of an effective pedagogical device taking into account all teachers in continuing education actions, the description with precision of the ideal portrait of the product envisaged for the Congolese educational system. This makes it possible to envisage continuing training actions with a view to developing required professional competences for the expected product. Our work has also shown that the effective professionalization of teachers leads to the professionalization of teaching work and the education system. To this end, set up a continuous training policy adapted to the pedagogical and administrative specificities of the Congo. and new ideas for managing training, this is one of the missions of the teachers in the Directorate General of Secondary Education, which should be supported by all agents. This policy is, without a doubt, possible and could be inspired by the suggestions presented in the second part of this work. However, it should be noted that our work has allowed us to identify the impact of continuing training on the professional skills of teachers in the context of secondary education only, it would be interesting to continue this work in the sense of the relationship between vocational training and the education system in the Congolese context. This could lead to the overhaul of the Congolese education system in order to link it to the current global context.

\section{References}

[1] Brousseau, M. et Laurin, P. (1997). La prise en charge de la formation continue par les enseignantes et enseignants est-elle possible ? Paris : Vie pédagogique.

[2] Chapelle, G.,Meuret, D. (2006). Améliorer l'école. Paris : PUF

[3] Eurydice. (1995). La formation continue des enseignants dans l'union européenne et dans les pays de l'AELE/EEE. Bruxelles : Unité européenne d'Eurodice

[4] Inchauspé, P. (1997). Relations entre formation professionnelle et système éducatif. Outremont : Société québécoise de développement de la main d'oeuvre

[5] Legendre, R. (1993). Dictionnaire actuel de l'éducation. Montreal : Guérin

[6] Masselter, G. (2004). Formation continue des enseignants $\mathrm{du}$ préscolaire et $\mathrm{du}$ primaire au Luxembourg. Luxembourg : MENFPS-SCRIPT

[7] Moussavou, G. (2015). La professionnalisation par l'expérience des enseignants sans formation initiale au Gabon. Paris : L'Harmattan

[8] Peretti, J.-M. (2002). Gestion des ressources humaines. Paris : 10è éd. Vuibert.

[9] Rousseau, J.-J. (1755). Discours sur l'origine de l'inégalité parmi les hommes. Paris : Naigeon

[10] Thelot, C. (1993). L'évaluation du système éducatif. Paris : Nathan

[11] Toussaint et Rodolphe, M.J. (2004). La notion de compétence en éducation et en formation : Fonctions et enjeux. Paris : L'Harmattan

\section{Legal Texts.}

[12] Law 25-95 of 17 November 1995 Modifying the School Law No. 008/90 of 6 September 1990 and reorganizing the education system in the Republic of Congo 